\title{
Characterization of sarcoma-like cells derived from endarterectomized tissues from patients with CTEPH and establishment of a mouse model of pulmonary artery intimal sarcoma
}

\author{
TAKAYUKI JUJO $^{1 *}$, SEIICHIRO SAKAO ${ }^{*}$, MASASHI KANTAKE ${ }^{1}$, MIKI MARUOKA $^{3}$, \\ NOBUHIRO TANABE ${ }^{1}$, YASUNORI KASAHARA ${ }^{1}$, KATSUSHI KUROSU ${ }^{1}$, \\ MASAHISA MASUDA $^{3}$, KENICHI HARIGAYA ${ }^{2}$ and KOICHIRO TATSUMI ${ }^{1}$
}

\author{
Departments of ${ }^{1}$ Respirology and ${ }^{2}$ Molecular and Tumor Pathology, Graduate School of Medicine, Chiba University, \\ Chuo-ku, Chiba 260-8670; ${ }^{3}$ Chiba Medical Center, National Hospital Organization, Chuo-ku, Chiba 260-8606, Japan
}

Received February 6, 2012; Accepted April 20, 2012

DOI: 10.3892/ijo.2012.1493

\begin{abstract}
In general, intravascular thrombus formation in the pulmonary arteries is considered to be the most common cause of chronic thromboembolic pulmonary hypertension (CTEPH). The current mainstay of therapy for patients with CTEPH is pulmonary endarterectomy (PEA). Recently, the existence of myofibroblast-like cells in endarterectomized tissues has been demonstrated. At the 2nd passage of these myofibroblast-like cells, a pleomorphic cell type was isolated. Pulmonary intimal sarcoma is a very uncommon neoplastic tumor thought to originate from subendothelial-mesenchymal cells of the pulmonary vascular wall. Because these pleomorphic cells were isolated from the pulmonary vascular beds, it is believed that the analysis of these cells may contribute to the understanding of pulmonary intimal sarcoma. We isolated cells from the endarterectomized tissue from patients with CTEPH and identified one type as sarcoma-like cells (SCLs). The SCLs were characterized as hyperproliferative, anchorage-independent, invasive and serum-independent. Moreover, C.B-17/lcr-scid/ scidJcl mice injected subcutaneously with SCLs developed solid, undifferentiated tumors at the site of injection, and those injected intravenously with SCLs via the tail vein developed tumors which grew along the intimal surface of the pulmonary vessels, thus, demonstrating the high tumorigenic potential of these cells. The behavior of SCLs indicated that these cells may have a vascular cell-like potential which can affiliate them with
\end{abstract}

Correspondence to: Dr Seiichiro Sakao, Department of Respirology (B2), Graduate School of Medicine, Chiba University, 1-8-1 Inohana, Chuo-ku, Chiba 260-8670, Japan

E-mail: sakaos@faculty.chiba-u.jp

*Contributed equally

Key words: pulmonary hypertension, thrombus, embolism, intimal sarcoma the intimal surface of the pulmonary artery, and which may be shared with pulmonary intimal sarcoma. A further investigation of this mouse model with SCLs may elucidate the mechanism(s) underlying the development of pulmonary intimal sarcoma.

\section{Introduction}

In general, pulmonary emboli originating from deep vein thrombosis are thought to have an important role in the development of chronic thromboembolic pulmonary hypertension (CTEPH) $(1,2)$. Organized and incorporated fibrous thrombi promote the complete obliteration of the pulmonary arteries, thus resulting in an increase in pulmonary vascular resistance. Therefore, the current mainstay of therapy for patients with CTEPH is pulmonary endarterectomy (PEA) (3).

Recently, the existence of not only myofibroblast-like cells, but also endothelial-like cells, in the endarterectomized tissues from patients with CTEPH has been demonstrated (4-6). Moreover, our recent study suggested that these myofibroblast-like cells might release substances that promote the endothelial-mesenchymal transition (EnMT) and/or induce EC dysfunction (7). Indeed, there were transitional cells which co-expressed both endothelial (CD31) and SM $[\alpha$-smooth muscle actin (SMA)] markers in these tissues from patients with CTEPH (7). At the 2nd passage of the myofibroblast-like cells, a pleomorphic cell type that varied in size and shape, and was characterized by a large nucleus, was isolated from the endarterectomized tissues of patients with CTEPH. Because these cells seemed to be hyperproliferative and anti-apoptotic, they were defined as sarcoma-like cells (SCL) (preliminary data). Pulmonary intimal sarcoma is a very uncommon neoplastic tumor of the cardiovascular system, and only about 125 cases have been reported in the literature (8). This tumor is thought to originate from subendothelial-mesenchymal cells of the pulmonary vascular wall (9). Immunohistochemical examinations of intimal sarcoma demonstrated that these tumors undergo endothelial, fibroblastic, or myofibroblastic differentiation (10). Some studies have demonstrated that 
intimal sarcomas have positive staining for $\alpha$-SMA (11), while others have indicated that they are only positive for vimentin, but not for desmin or $\alpha$-SMA (12). The pathobiology of pulmonary intimal sarcoma remains largely unknown because of its rarity.

Because the SCL were isolated from endarterectomized tissues, i.e., the pulmonary vascular beds, of patients with $\mathrm{CTEPH}$, it was hypothesized that the analysis of these cells may contribute to our understanding of pulmonary intimal sarcoma, which was defined as a neoplasm arising in the tunica intima of the pulmonary arteries. The aim of this study was to investigate the characteristics of SCL in vivo and in vitro.

\section{Materials and methods}

Cell isolation. Endarterectomized tissues from patients with CTEPH were obtained following PEA performed by M.M. at the Chiba Medical Center, Japan. The details of the cell isolation techniques have been described previously (4). The study was approved by the Research Ethics Committee of Chiba University School of Medicine, and written informed consent was given by all subjects.

Cell lines and reagents. Normal human lung fibroblasts (NHLF) and human pulmonary microvascular endothelial cells (HPMVEC) were purchased from Lonza Inc. (Allendale, NJ, USA) and cultured using EGM and fibroblast growth medium (FGM) supplemented with 5\% fetal bovine serum (Lonza Inc.). A549 (lung cancer cell line) cells and HT1080 (fibrosarcoma cell line) cells were obtained from Takara Biomedical (Othsu, Shiga, Japan) and cultured in RPMI-1640 medium supplemented with $5 \%$ fetal bovine serum (Lonza Inc.). The following $\mathrm{Ab}$ were used for the analyses: mouse anti-vimentin (1:200, Dako, Carpinteria, CA, USA), mouse anti-human desmin (1:100, Dako), mouse anti- $\alpha$-SM-actin ( $\alpha$ SMA) (1:1,000, Sigma-Aldrich, St. Louis, MO, USA), mouse antihuman Ki-67 (1:100, BD Biosciences Pharmingen, San Diego, CA, USA), anti-mouse IgG conjugated with Rhodamine dye (1:500, Molecular Probes, Eugene, OR, USA), rabbit anti-von Willebrand factor (factor VIII) (1:1,000, Dako), and an antirabbit IgG conjugated with Alexa-488 fluorescent dye (1:500, Molecular Probes). The Bromodeoxyuridine (BrdU) Flow Kit and the BD BioCoat ${ }^{\mathrm{TM}}$ FluoroBlok $^{\mathrm{TM}}$ Invasion System (24-multiwells) were purchased from BD Biosciences.

Immunofluorescent staining. The cells were fixed in a 1:1 mixture of methanol and acetone and incubated with the primary antibodies, followed by incubation with the secondary antibodies. Additional details about the method used for immunofluorescent staining have been described previously (4).

BrdU-7-amino-actinomycin D binding assay. The BrdU Flow Kit was used to detect the rate of DNA synthesis. The details of this assay technique have been described previously (4).

Colony-forming assay. Six-well flat-bottomed plates with a twolayer soft agar system including a total of $1 \times 10^{4}$ cells/well in a volume of $1.5 \mathrm{ml} /$ well in the upper layer were adapted for the colony-forming assay. Additional details on the method used for this assay have been described previously (4).
Cell invasion and migration assay. The BD BioCoat FluoroBlok Invasion System (24-multiwell) was used for the cell migration assays. The details of the cell invasion and migration assay techniques have been previously described (4).

Serum starvation. The cells at passage 4 were seeded at $1 \times 10^{5}$ in $25-\mathrm{cm}^{2}$ flasks and were incubated with serum-free medium for the indicated incubation periods. The details of the serum starvation assay techniques have been described previously (4).

Tumorigenicity studies. Adult male C.B-17/lcr-scid/scidJcl (SCID) mice were purchased from a commercial vendor. Tumors were generated by subcutaneous injection of SCL and intravenous tail vein injection of SCL and A549 into SCID mice $(n=10$ per group, $20 \pm 2.5 \mathrm{~g})$ under Nembutal anesthesia $(50 \mathrm{mg} / \mathrm{ml})$. At a subcutaneous inoculation concentration of $1 \times 10^{6}$ cells per mouse, the SCL consistently produced subcutaneous tumors. At an intravenous injection concentration of $2 \times 10^{6}$ cells per mouse, the SCL and A549 cells consistently produced intravenous and lung tumors. The mice were sacrificed, and the tumors and the organs were quickly isolated and excised on the appropriate days after intravenous injection. After that, they were fixed in $10 \%$ formalin for $48 \mathrm{~h}$, and embedded in paraffin. These tissues were sectioned and prepared for the histological analysis. The animal protocol was approved by the Animal Care and Use Committee of Chiba University School of Medicine.

Labeling of SCL with PKH-26. The lipophilic fluorescent PKH dye, PKH-26 (Sigma-Aldrich), was used to label the SCL. The PKH26 dye was diluted at the recommended concentration and mixed with the SLC for $5 \mathrm{~min}$, according to manufacturer's instructions. These cells were injected intravenously via the tail vein of SCID mice and, on day 21, the mice were sacrificed, and their lungs were quickly isolated and excised. The existence of PKH positive SCL with DAPI staining was confirmed under fluorescent microscopy.

PCR array analysis. RT2 Profiler ${ }^{\mathrm{TM}}$ PCR Arrays (SABiosciences, Frederick, MD, USA) were used to analyze the expression of a focused panel of genes involved in various biological processes. The 96-well plate extracellular matrix and adhesion molecules PCR array (PAHS-013) which profiles the expression of 84 key genes involved in the formation of the extracellular matrix and adhesion molecules, were selected to detect the differential expression of genes between SCL and A549. Additional details on the method used for this analysis have been described previously (7).

Statistical analysis. The statistical analyses were performed using data from at least three independent experiments. The results are expressed as the means \pm SEM. The data were analyzed using Student's t-test, as appropriate. A value of $\mathrm{p}<0.05$ was considered to be significant for all tests.

\section{Results}

The cellular composition of endarterectomized tissue from CTEPH patients. As shown previously, a few different cell types were isolated from the endarterectomized tissues in each of the 15 patients with CTEPH (4). One of them was determined 
A

SCL

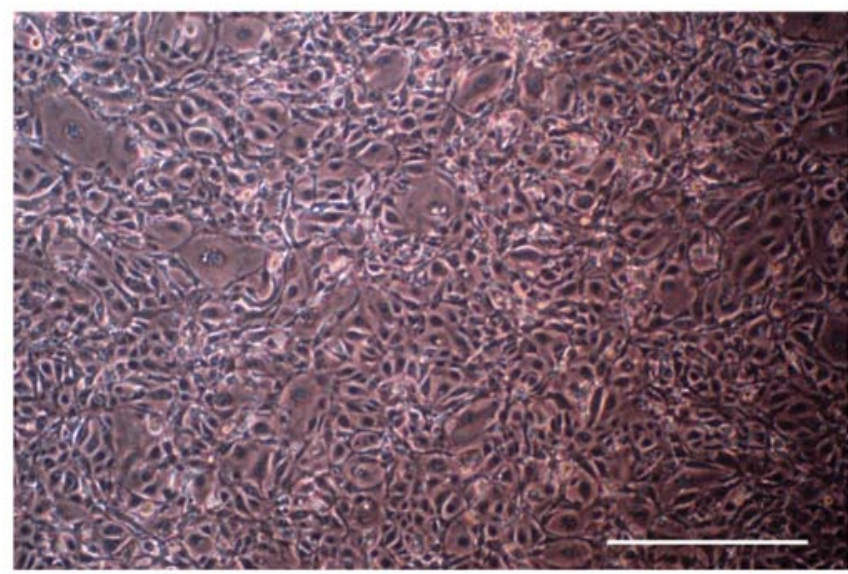

B

SCL
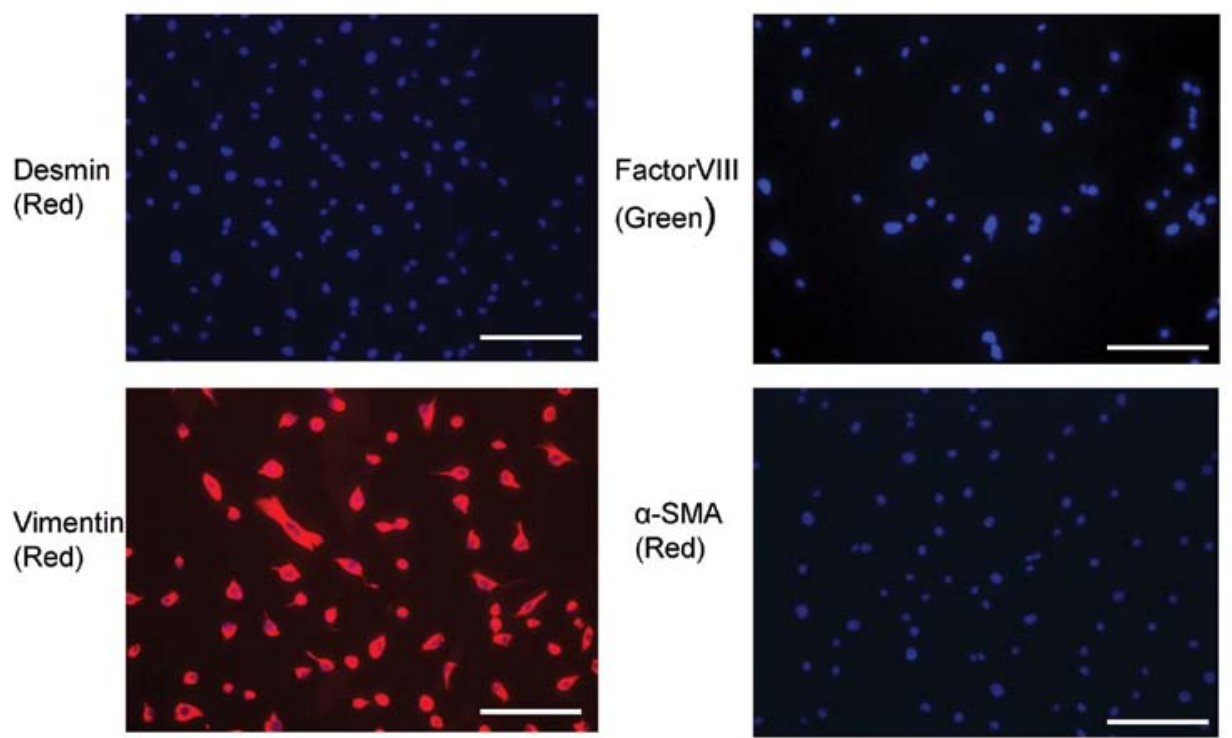

Figure 1. Characterization of the sarcoma-like cells (SCL) from endarterectomized tissue. (A) The SCL from endarterectomized tissue were microscopically assessed. The magnification was x100. Scale bar, $100 \mu \mathrm{m}$. (B) SCL derived from endarterectomized tissue were assessed by immunofluorescent staining for desmin, vimentin, factor VIII and $\alpha$-SMA to confirm the phenotypes of the cells. DAPI staining is shown in blue. The magnification was $\mathrm{x} 200$. Scale bar, $50 \mu \mathrm{m}$.

morphologically to be the myofibroblast-like cells (spindleshape with cytoplasmic extensions) (4). At the 2nd passage of the myofibroblast-like cells, another cell type that varied in size and shape and was characterized by a large nucleus, was isolated from one patient described in a previous study (4). These cells had the morphology of SCL (Fig. 1A). The cells outgrown from the thrombotic material were further characterized by immunohistochemical staining for desmin, vimentin, factor VIII and $\alpha$ SMA. The SCL were factor VIII, desmin and $\alpha$ SMA negative, and vimentin positive (Fig. 1B).

Proliferative activity of SCL. The SCL grew without cell-cell contact inhibition and started piling up and forming foci in human fibronectin coated culture dishes $(6 \mathrm{~cm}$ in diameter $)$ (Fig. 1C). In order to confirm their proliferative activity, the number of proliferating cells which had synthesized DNA was assessed by flow cytometry by immunofluorescent staining of the incorporated BrdU. The number of BrdU positive cells was increased in the SCL, but there was no increase in the incorpo- ration of BrdU by the HPMVEC and NHLF which were used as controls (Fig. 1D).

Anchorage-independent growth of the SCL. Because the growth of the SCL without cell-cell contact inhibition suggested that they would exhibit anchorage-independent growth, we investigated the ability of these cells to form colonies in soft agar. The SCL showed anchorage-independence in the soft agar colony formation assays (Fig. 1E). The colony formation was particularly prominent in the SCL compared with the HPMVEC and NHLF (Fig. 1F).

Invasive and migratory activity of the SCL. Because the SCL exhibited hyperproliferative potential and the ability to undergo anchorage-independent growth, which reflected cancer-related properties (13), we assessed the invasion and migration of the SCL. Using the BD BioCoat FluoroBlok Invasion assay, the SCL, an invasive lung cancer cell line (A549), an invasive fibrosarcoma cell line (HT1080), and the NHLF were allowed to 
C

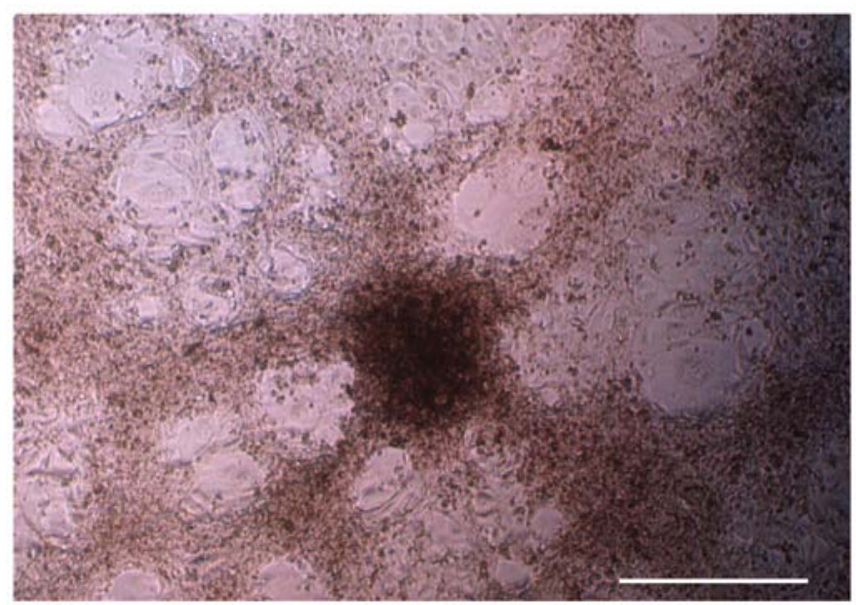

$\mathrm{E}$
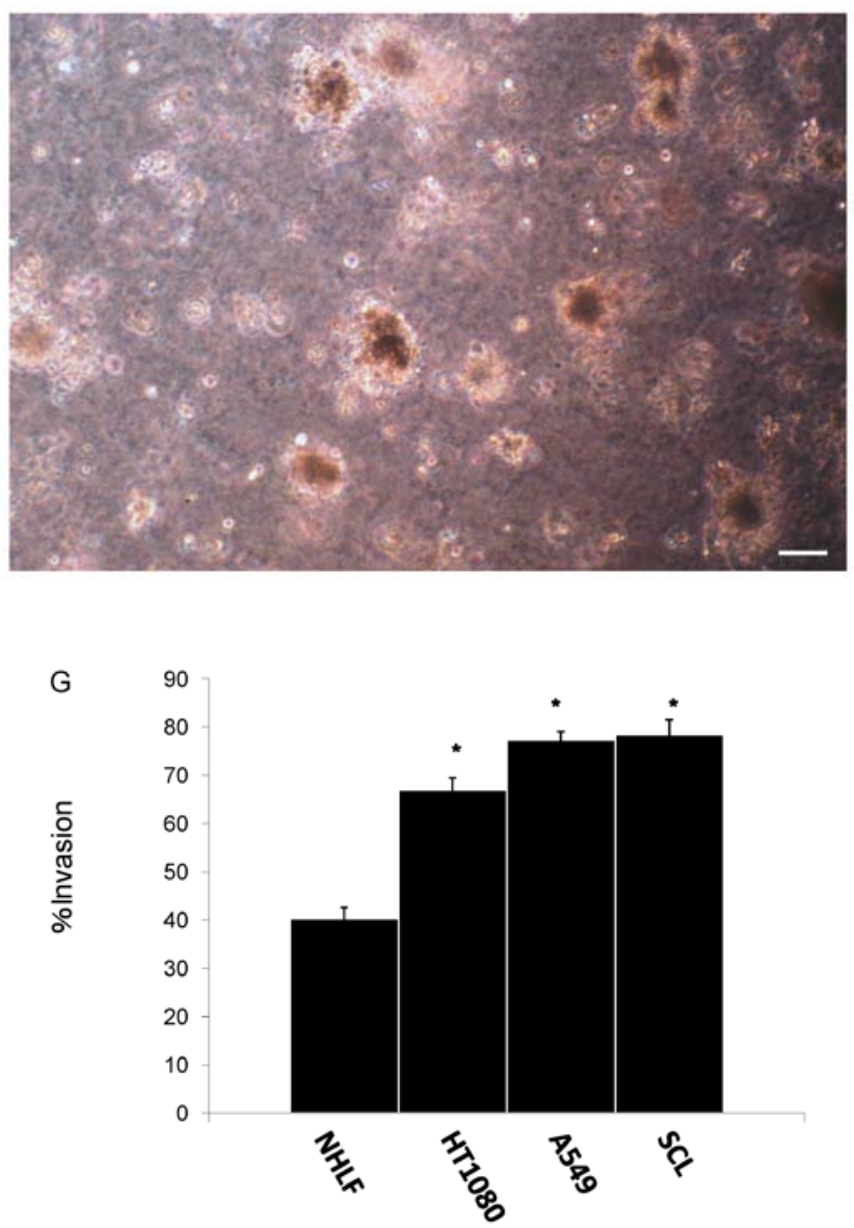

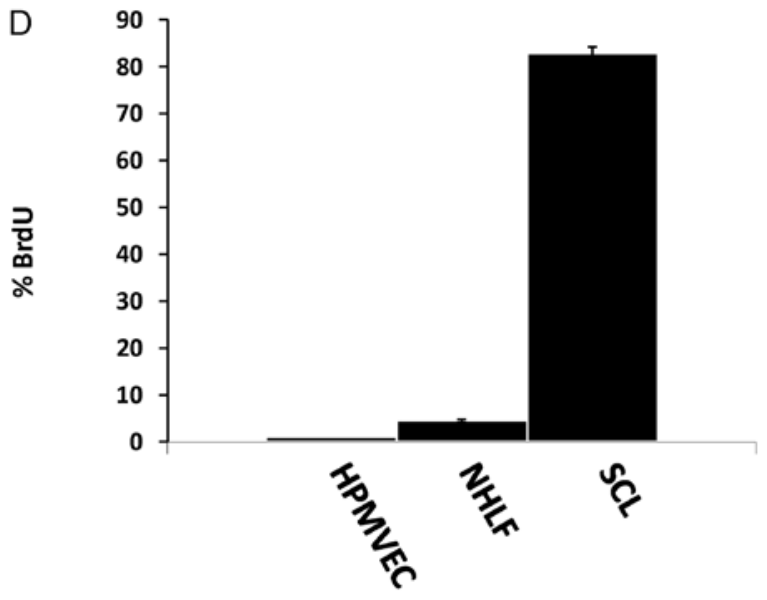

*, P<0.05 vs HPMVEC or NHLF

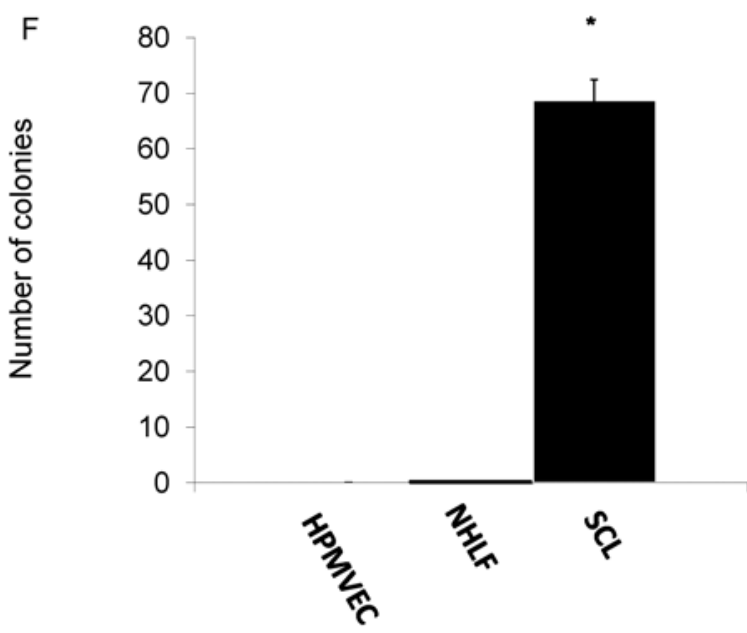

$*, \mathrm{P}<0.05$ vs HPMVEC or NHLF
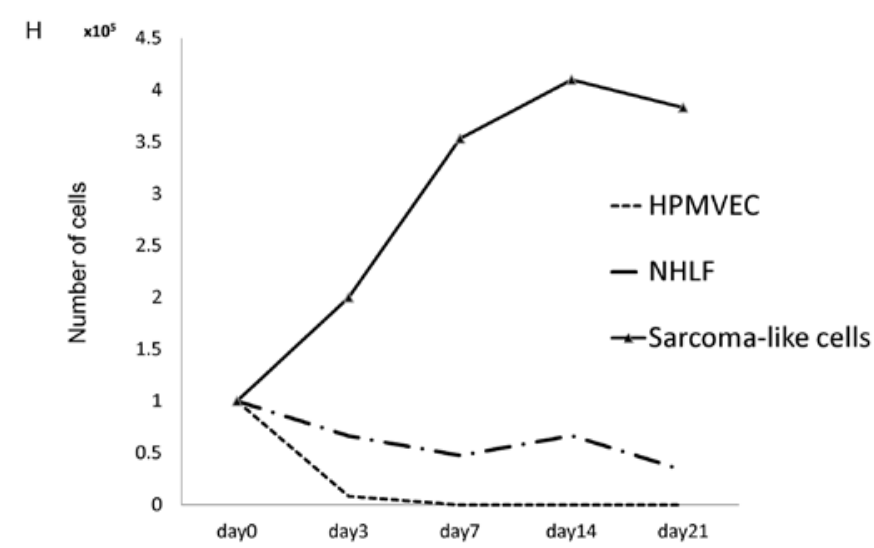

$*, \mathrm{P}<0.05$ vs NHLF

Figure 1. Continued. (C) Light microscopic examination of the SCL at the 3rd passage. The magnification was x100. Scale bar, $100 \mu \mathrm{m}$. (D) Quantification of the proliferating SCL at the 4th passage. The individual cells that had synthesized DNA were determined by the immunofluorescent staining of incorporated bromodeoxyuridine (BrdU). The incorporated BrdU was stained with specific anti-BrdU fluorescent antibodies. The levels of cell-associated BrdU were measured by flow cytometry; error bars represent the \pm SD from experiments done in triplicate. ${ }^{*} p<0.05$. (E) The results of the colony-forming assay. SCL at the 4th passage were trypsinized and replated on soft agar. Microphotographs show the colonies grown in soft agar for 2 weeks. The magnification was $\mathrm{x} 40$. Scale bar, $100 \mu \mathrm{m}$. (F) The numbers of colonies per microscopic field were counted; error bars represent the \pm SD from experiments done in triplicate. ${ }^{*} \mathrm{p}<0.05$. (G) The results from the cell invasion and migration assay in SCL. For the BD BioCoat FluoroBlok Invasion assay, NHLF, an invasive fibrosarcoma cell line (HT1080), an invasive lung cancer cell line (A549) and the SCL were allowed to invade for $16 \mathrm{~h}$; error bars represent the \pm SD from experiments done in triplicate. " $\mathrm{p}<0.05$. (H) Serum starvation. A comparison of the growth of HPMVEC, NHLF and SCL in the absence of serum. Cells at passage 4 were seeded at $1 \times 10^{5}$ in $25-\mathrm{cm}^{2}$ flasks on day 0 and were incubated with serum-free medium for the indicated incubation periods. On each indicated day, a flask was trypsinized, and the cells counted. The average values of three experiments are shown. SCL, sarcoma-like cells; HPMVEC, human pulmonary microvascular endothelial cells; NHLF, normal human lung fibroblasts. 


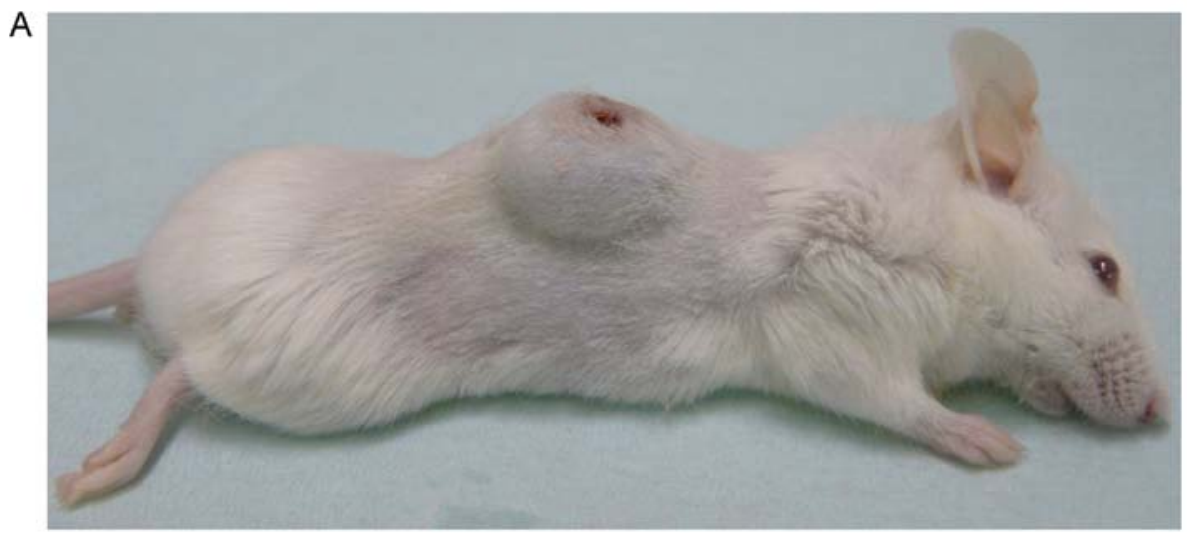

B

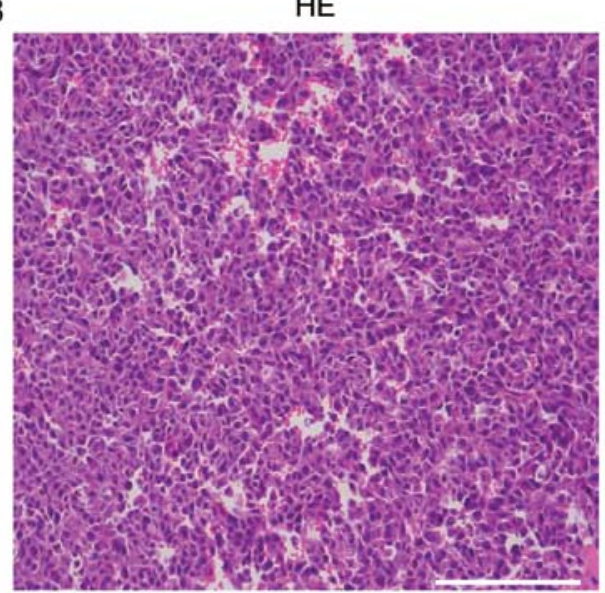

$\mathrm{Ag}$

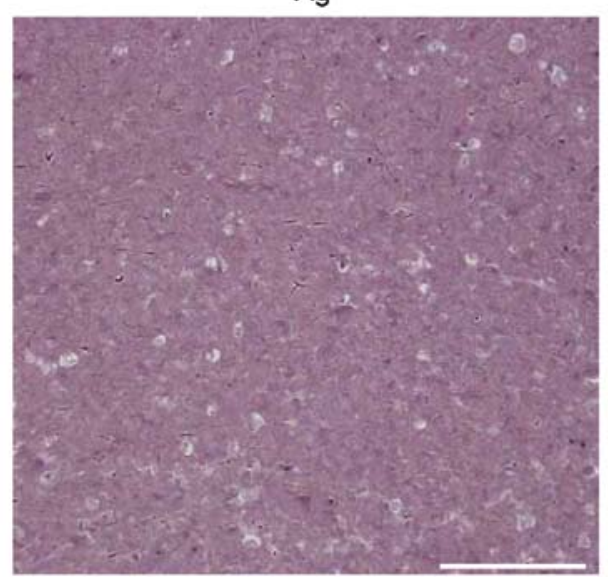

C

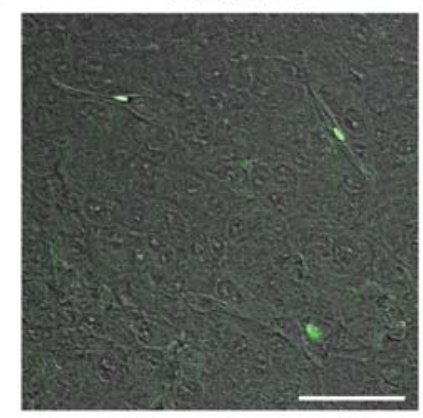

Vimentin

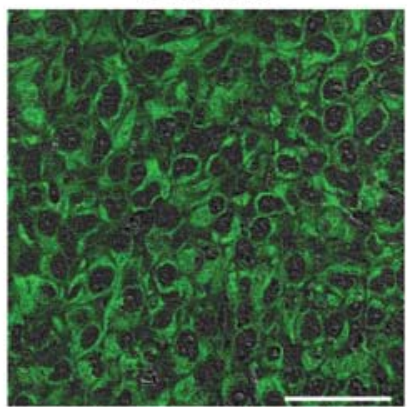

a-SMA

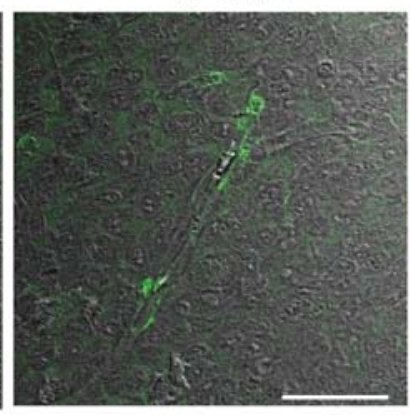

ki67

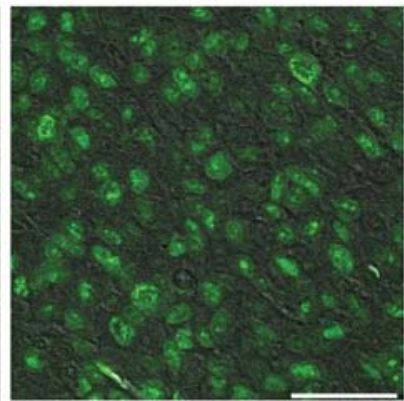

Figure 2. The tumorigenicity of subcutaneously injected SCL. (A) Microphotographs of tumors from a male C.B-17/lcr-scid/scidJcl (SCID) mouse injected subcutaneously with sarcoma-like cells (1x10 cells per mouse). (B) Hematoxylin/eosin and silver staining of a tumor derived from sarcoma-like cells. Hematoxylin/eosin and silver staining revealed the presence of pleomorphic cells and immature blood vessels (sarcomatous vessels lacking endothelial cells) which favored the escape of tumor metastatic cells and were characterized by reduced collagen production (see Fig. 3B). The magnification was x100. Scale bar, $100 \mu \mathrm{m}$. (C) Immunofluorescent staining for factor VIII, $\alpha$ SMA, desmin, vimentin and Ki67 of a tumor derived from sarcoma-like cells. The magnification was x200. Scale bar, $50 \mu \mathrm{m}$. ${ }^{*}$ The cells stained positively were smooth muscle cells in a SCID mouse. 
A day1
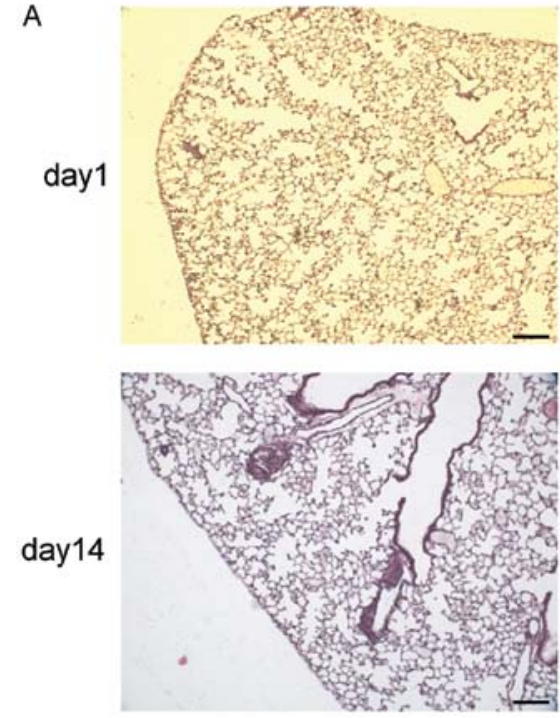

B

day1
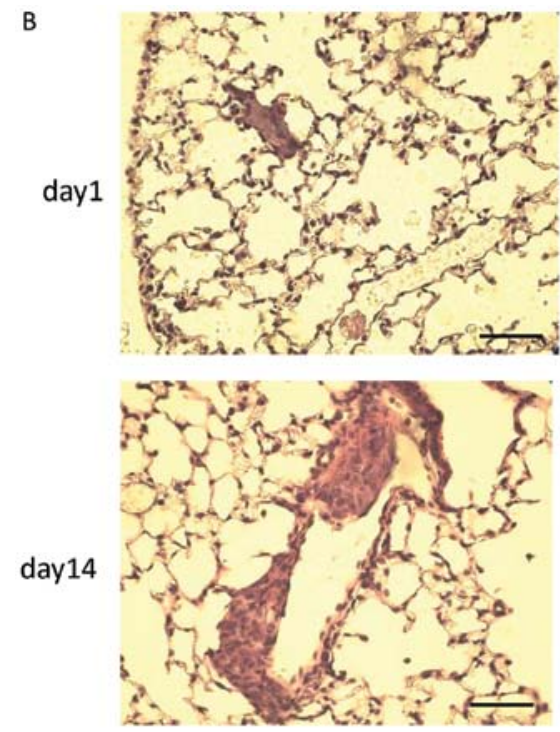

day 7

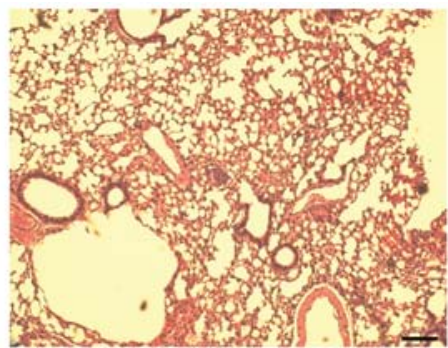

day21

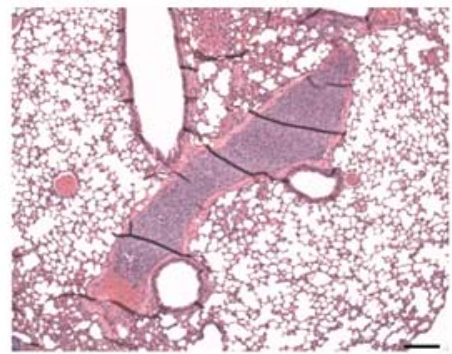

day 7

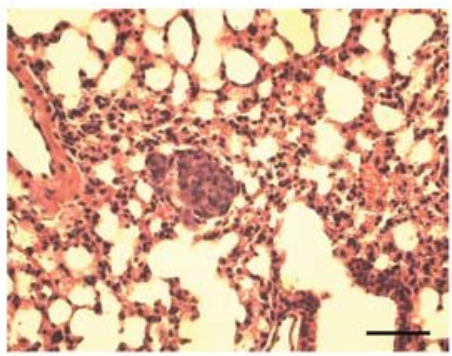

day 21

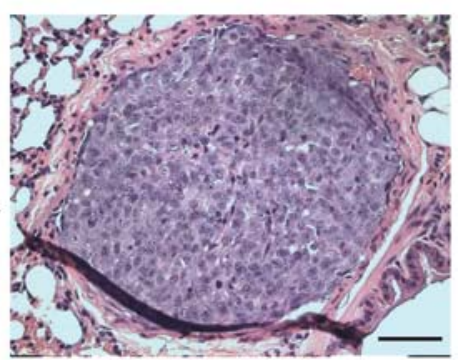

Figure 3. The tumorigenicity of intravenously injected SCL. (A and B) Hematoxylin/eosin staining of lung tumors from a male C.B-17/lcr-scid/scidJcl (SCID) mouse injected intravenously with SCL $\left(2 \times 10^{6}\right.$ cells per mouse). Hematoxylin/eosin staining suggested the presence of pleomorphic cells in the pulmonary vessels that increased and migrated in a time-dependent manner. (A) The magnification was $\mathrm{x} 40$. Scale bar, $100 \mu \mathrm{m}$. (B) The magnification was $\mathrm{x} 100$. Scale bar, $50 \mu \mathrm{m}$.

invade for $16 \mathrm{~h}$. The SCL showed high invasive and migratory activity, similar to the HT1080 and A549 cells in comparison to the NHLF (Fig. 1G). These findings suggested that the SCL might share an in vitro invasive potential with sarcomas and cancer cell lines.

Serum-independent growth of SCL. In the absence of serum, the HPMVEC could not survive, and rapidly underwent apoptosis. Likewise, the NHLF stopped proliferating and gradually died (Fig. 1H). However, the SCL survived indefinitely in the absence of serum and kept proliferating (Fig. $1 \mathrm{H})$.

Subcutaneous tumorigenicity of SCL. In order to test whether these proliferating cells displayed tumorigenic potential, the SCL were injected subcutaneously into SCID mice. Within 4 weeks after s.c. injection (i.e., when tumors had reached a diameter of about $2 \mathrm{~cm}$ ), 8/8 animals injected with the SCL had developed solid, differentiated tumors at the site of the injection
(Fig. 2A), thus demonstrating the high tumorigenic potential of the sarcoma-like cells.

Hematoxylin/eosin $(\mathrm{H} \& \mathrm{E})$ and silver staining of the sections of a tumor revealed the presence of pleomorphic cells and immature blood vessels (sarcomatous vessels lacking endothelial cells) which favored the escape of tumor metastatic cells and were characterized by reduced collagen production (Fig. 2B). Immunofluorescent staining demonstrated that the cells within the tumors were of mesenchymal origin, neither EC nor SMC, since they were stained negatively for factor VIII, $\alpha$ SMA, and desmin (the cells stained positively were SMC in a SCID mouse) and positively for vimentin (Fig. 2C). The pleomorphic cells were hyperproliferative, as indicated by their expression of the proliferation marker, Ki67 (Fig. 2C).

Tumorigenicity of intravenously injected SCL and A549 cells. In order to test whether the SCL can grow along the intimal surface of the pulmonary artery in a sheet-like form and result in 
C
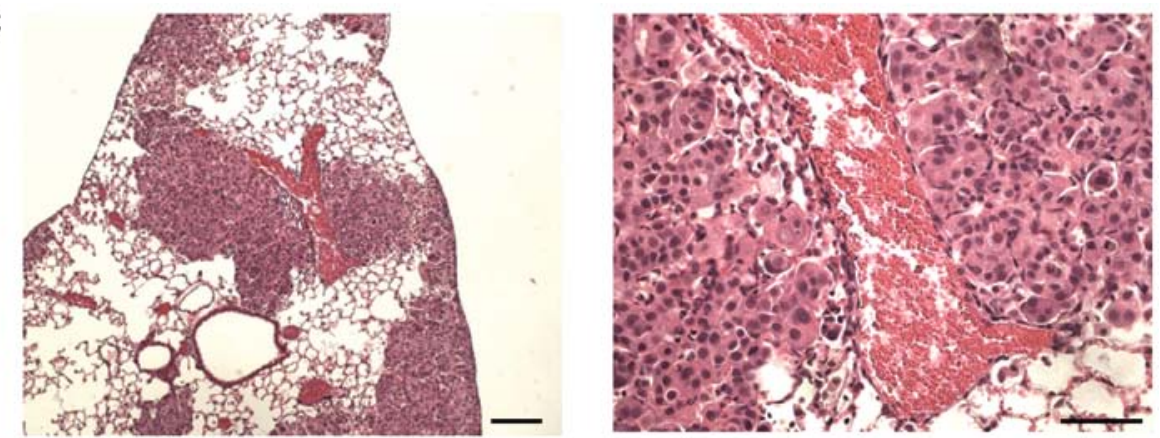

D
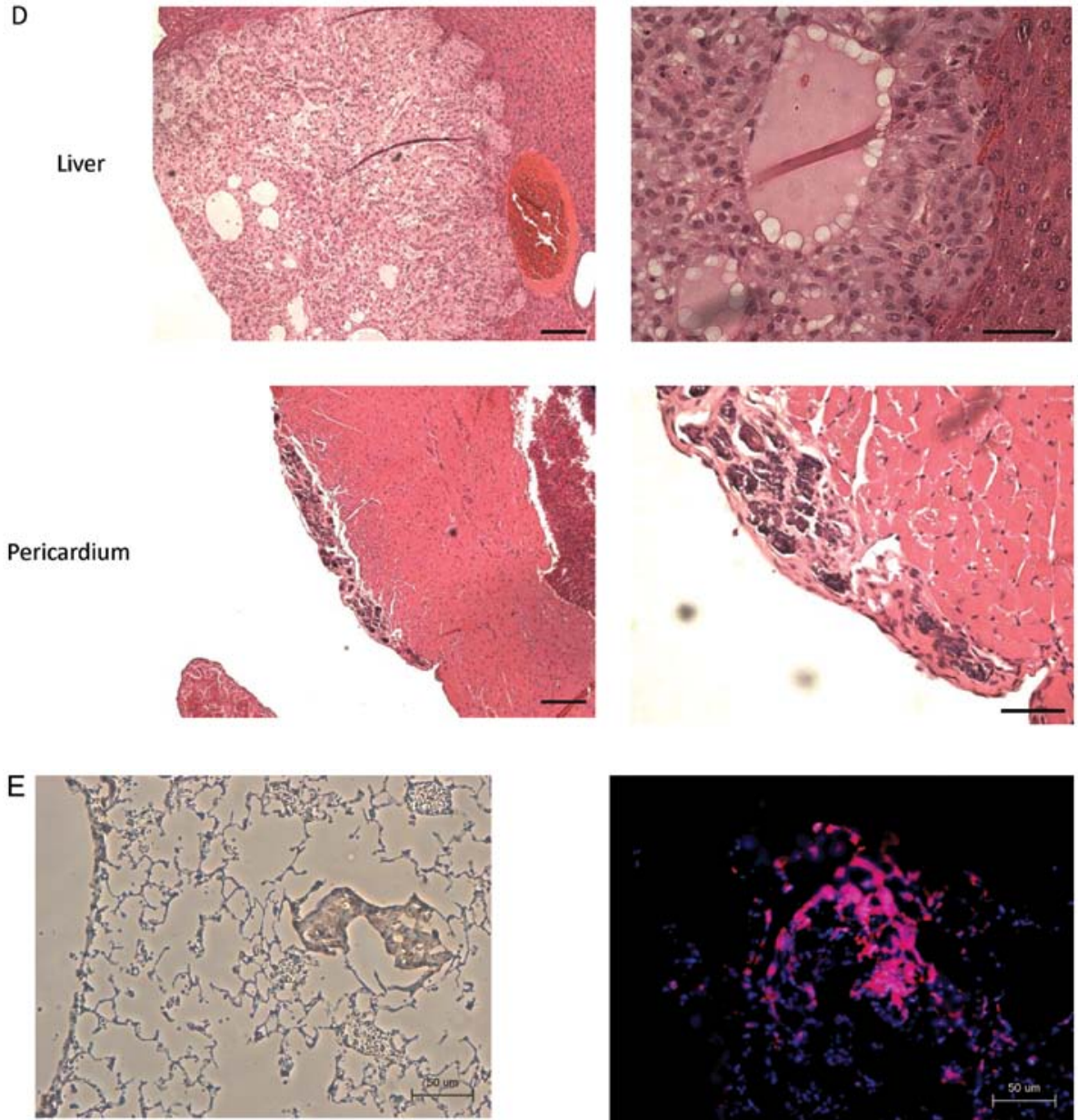

IHC anti-human vimentin
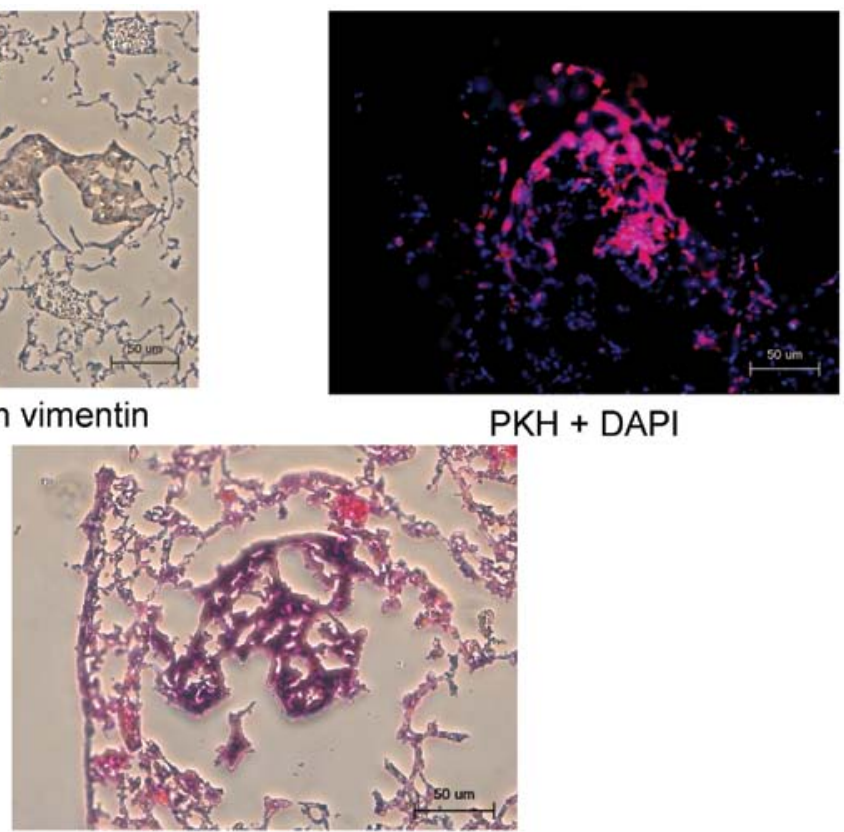

$\mathrm{HE}$

Figure 3. Continued. (C) Hematoxylin/eosin staining of lung tumors from a male C.B-17/lcr-scid/scidJcl (SCID) mouse injected intravenously with A549 cells ( $2 \times 10^{6}$ cells per mouse). Hematoxylin/eosin staining revealed the presence of pleomorphic cells within the lung parenchyma. Left: the magnification was $\mathrm{x} 40$, scale bar, $100 \mu \mathrm{m}$. Right: the magnification was x100, scale bar, $50 \mu \mathrm{m}$. (D) Hematoxylin/eosin staining of the liver and pericardial tumors from a male C.B-17/lcr-scid/ scidJcl (SCID) mouse injected intravenously with A549 cells (2x10 6 cells per mouse). Hematoxylin/eosin staining revealed the presence of pleomorphic cells in the liver and pericardium. Left: the magnification was $\mathrm{x} 40$, scale bar, $100 \mu \mathrm{m}$. Right: the magnification was x100, scale bar, $50 \mu \mathrm{m}$. (E) Immunohistochemical staining with an anti-human vimentin antibody, double immunofluorescent detection of PKH26 and DAPI, and hematoxylin/eosin staining of lung tumors from a male C.B-17/lcr-scid/scidJcl (SCID) mouse injected intravenously with SCL ( $2 \times 10^{6}$ cells per mouse). These findings indicated that pleomorphic cells originated from the SCL which were injected intravenously via a tail vein. The magnification was x100, scale bar, $50 \mu \mathrm{m}$. 
Table I. Human extracellular matrix and adhesion molecules PCR array.

\begin{tabular}{|c|c|c|c|c|}
\hline Biological process description & Gene name & Gene symbol & Public ID & P-value \\
\hline $\begin{array}{l}\text { Extracellular matrix proteins: } \\
\text { collagens \& ECM structural constituents }\end{array}$ & Collagen, type IV, alpha 2 & COL4A2 & NM_001846 & 0.049403 \\
\hline $\begin{array}{l}\text { Extracellular matrix proteins: } \\
\text { collagens \& ECM structural constituents }\end{array}$ & Collagen, type VI, alpha 1 & COL6A1 & NM_001848 & 0.003689 \\
\hline $\begin{array}{l}\text { Cell adhesion molecules: } \\
\text { cell-cell adhesion }\end{array}$ & Collagen, type VI, alpha 2 & COL6A2 & NM_001849 & 0.031248 \\
\hline $\begin{array}{l}\text { Extracellular matrix proteins: } \\
\text { collagens \& ECM structural constituents }\end{array}$ & Fibronectin 1 & FN1 & NM_002026 & 0.005507 \\
\hline $\begin{array}{l}\text { Cell adhesion molecules: } \\
\text { transmembrane molecules }\end{array}$ & $\begin{array}{l}\text { Integrin, alpha } 2(\mathrm{CD} 49 \mathrm{~B}, \text { alpha } 2 \\
\text { subunit of VLA-2 receptor) }\end{array}$ & ITGA2 & NM_002203 & 0.004663 \\
\hline $\begin{array}{l}\text { Cell adhesion molecules: } \\
\text { transmembrane molecules }\end{array}$ & $\begin{array}{l}\text { Integrin, alpha } 3 \text { (antigen CD } 49 C \text {, } \\
\text { alpha } 3 \text { subunit of VLA-3 receptor) }\end{array}$ & ITGA3 & NM_002204 & 0.037106 \\
\hline $\begin{array}{l}\text { Cell adhesion molecules: } \\
\text { transmembrane molecules }\end{array}$ & $\begin{array}{l}\text { Integrin, alpha } 4 \text { (antigen CD49D, } \\
\text { alpha } 4 \text { subunit of VLA-4 receptor) }\end{array}$ & ITGA4 & NM_000885 & 0.005012 \\
\hline $\begin{array}{l}\text { Cell adhesion molecules: } \\
\text { transmembrane molecules }\end{array}$ & $\begin{array}{l}\text { Integrin, alpha } 5 \text { (fibronectin } \\
\text { receptor, alpha polypeptide) }\end{array}$ & ITGA5 & NM_002205 & 0.048419 \\
\hline $\begin{array}{l}\text { Extracellular matrix proteins: } \\
\text { ECM proteases inhibitors }\end{array}$ & Kallmann syndrome 1 sequence & KAL1 & NM_000216 & 0.005779 \\
\hline $\begin{array}{l}\text { Extracellular matrix proteins: } \\
\text { basement membrane constituents }\end{array}$ & Laminin, alpha 1 & LAMA1 & NM_005559 & 0.014549 \\
\hline $\begin{array}{l}\text { Extracellular matrix proteins: } \\
\text { basement membrane constituents }\end{array}$ & Laminin, beta 3 & LAMB3 & NM_000228 & 0.009781 \\
\hline $\begin{array}{l}\text { Cell adhesion molecules: } \\
\text { transmembrane molecules }\end{array}$ & $\begin{array}{l}\text { Matrix metallopeptidase } 14 \\
\text { (membrane-inserted) }\end{array}$ & MMP14 & NM_004995 & 0.049414 \\
\hline \multicolumn{5}{|l|}{$\begin{array}{l}\text { Extracellular matrix proteins: } \\
\text { ECM proteases }\end{array}$} \\
\hline $\begin{array}{l}\text { Extracellular matrix proteins: } \\
\text { basement membrane constituents }\end{array}$ & $\begin{array}{l}\text { Secreted protein, acidic, } \\
\text { cysteine-rich (osteonectin) }\end{array}$ & SPARC & NM_003118 & 0.029498 \\
\hline $\begin{array}{l}\text { Extracellular matrix proteins: } \\
\text { ECM proteases inhibitors }\end{array}$ & TIMP metallopeptidase inhibitor 2 & TIMP2 & NM_003255 & 0.026376 \\
\hline $\begin{array}{l}\text { Extracellular matrix proteins: } \\
\text { other ECM molecules }\end{array}$ & Tenascin $\mathrm{C}$ & TNC & NM_002160 & 0.014765 \\
\hline
\end{tabular}

Functional classification of highly expressed genes in SCLs in comparison to A549.

artery occlusion, we investigated the time course of cell growth within the pulmonary artery in comparison to A549 cells.

Hematoxylin/eosin staining of the sections of a lung revealed the presence of pleomorphic cells within the peripheral vessels on day 1 , thus suggesting that they were trapped in the pulmonary arteries after intravenous injection [Fig. 3A (small magnification) and B (large magnification)]. The cells spread in a time-dependent manner, and were detected in more distal pulmonary arteries on day 7 , grew along the intimal surface of the pulmonary artery in a sheet-like form on day 14, and resulted in artery occlusion on day 21 (Fig. 3A and B). To our surprise, there were no other microscopically visible lesions in any other organs on day 28 after intravenous injection (data not shown).

Hematoxylin/eosin stain demonstrated that there were no pleomorphic cells within the pulmonary vessels on day 21 after intravenous injection of A549 cells. However, these cells developed tumor-like lesions within the lung parenchyma (Fig. 3C).
Moreover, there were visible tumor-like lesions within not only the lungs, but also the liver and pericardium (Fig. 3D).

The origin of pleomorphic cells in the pulmonary vessels. To determine the origin of these pleomorphic cells, immunohistochemical staining with an anti-human vimentin antibody and double immunofluorescent detection of PKH26 and DAPI using fluorescence microscopy were performed. The H\&E staining of the sections of a lung indicated the presence of pleomorphic cells in the pulmonary vessels (Fig. 3E). These occlusive lesions were composed of some anti-human vimentin positive cells and some PKH26 positive cells (Fig. 3E), thus indicating that these pleomorphic cells could originate from the SCL which were injected intravenously via a tail vein.

The gene expression of extracellular matrix and adhesion molecules by the SCL and A549 cells as determined by a PCR array. The different growth patterns between the SCL and A549 cells 
Table II. Human extracellular matrix and adhesion molecules PCR array.

\begin{tabular}{|c|c|c|c|c|}
\hline Biological process description & Gene name & Gene symbol & Public ID & P-value \\
\hline $\begin{array}{l}\text { Cell adhesion molecules: } \\
\text { other adhesion molecules }\end{array}$ & Contactin 1 & CNTN1 & NM_001843 & 0.004029 \\
\hline $\begin{array}{l}\text { Cell adhesion molecules: } \\
\text { other adhesion molecules }\end{array}$ & Collagen, type XII, alpha 1 & COL12A1 & NM_004370 & 0.014824 \\
\hline $\begin{array}{l}\text { Cell adhesion molecules: } \\
\text { cell-cell adhesion }\end{array}$ & Collagen, type I, alpha 1 & COL1A1 & NM_000088 & 0.039601 \\
\hline $\begin{array}{l}\text { Cell adhesion molecules: } \\
\text { other adhesion molecules }\end{array}$ & Versican & VCAN & NM_004385 & 0.014957 \\
\hline $\begin{array}{l}\text { Cell adhesion molecules: } \\
\text { transmembrane molecules }\end{array}$ & Integrin, alpha 1 & ITGA1 & NM_181501 & 0.015272 \\
\hline $\begin{array}{l}\text { Cell-matrix adhesion: } \\
\text { cell adhesion molecules }\end{array}$ & Integrin, alpha 6 & ITGA6 & NM_000210 & 0.01777 \\
\hline \multicolumn{5}{|l|}{$\begin{array}{l}\text { Transmembrane molecules } \\
\text { cell-matrix adhesion }\end{array}$} \\
\hline $\begin{array}{l}\text { Extracellular matrix proteins: } \\
\text { ECM proteases }\end{array}$ & $\begin{array}{l}\text { Matrix metallopeptidase } 7 \\
\text { (matrilysin, uterine) }\end{array}$ & MMP7 & NM_002423 & 0.002811 \\
\hline $\begin{array}{l}\text { Cell adhesion molecules: } \\
\text { cell-matrix adhesion }\end{array}$ & Secreted phosphoprotein 1 & SPP1 & NM_000582 & 0.000198 \\
\hline $\begin{array}{l}\text { Extracellular matrix proteins: } \\
\text { other ECM molecules }\end{array}$ & $\begin{array}{l}\text { Transforming growth factor, } \\
\text { beta-induced, } 68 \mathrm{kDa}\end{array}$ & TGFBI & NM_000358 & 0.003123 \\
\hline
\end{tabular}

Functional classification of low expressed genes in SCLs in comparison to A549.
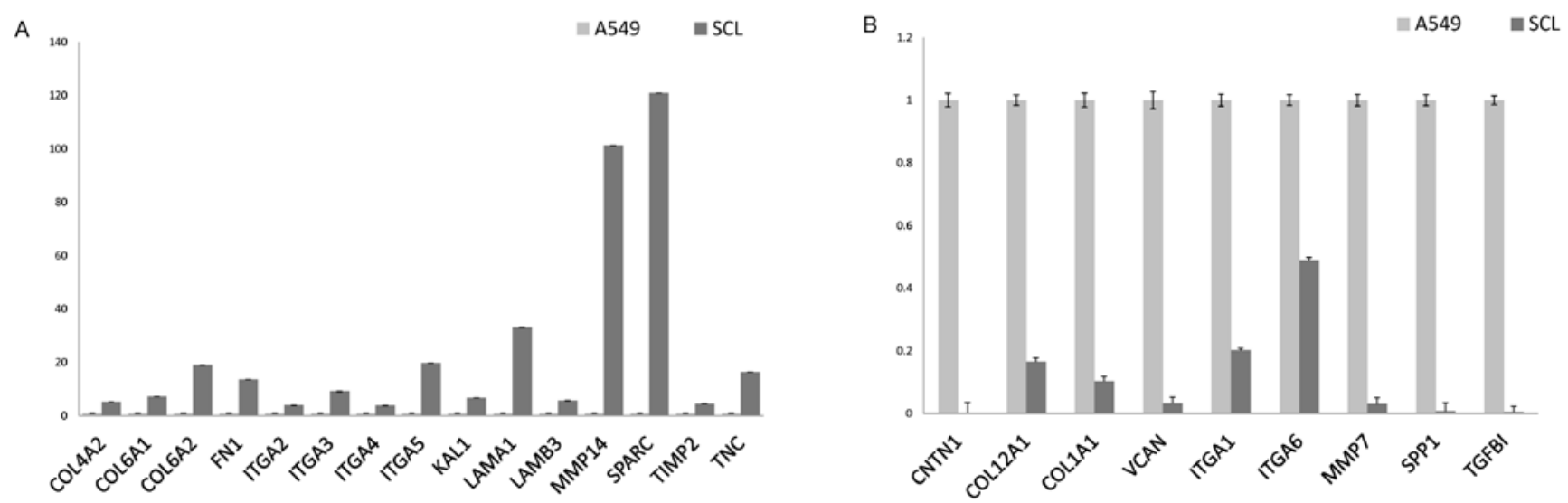

Figure 4. The results of the extracellular matrix and adhesion molecule PCR array. (A) The genes that were more highly expressed in SCL in comparison to A549 cells. There were increases in the expression of 15 extracellular matrix and adhesion molecule-related genes in SCL in comparison to A549 cells (P<0.05; $\mathrm{n}=3$ ). See Table I for definitions of the abbreviations. (B) The genes that were less expressed in the SCL in comparison to A549 cells. There were decreases in the expression of 9 extracellular matrix and adhesion molecule-related genes in the SCL in comparison to the A549 cells $(\mathrm{P}<0.05 ; \mathrm{n}=3)$. See Table II for definitions of the abbreviations .

after intravenous injection suggested that the cells have different pathophigiological behaviors, which may reflect a difference between epithelial and mescenchymal tumors. Therefore, an extracellular matrix and adhesion molecules PCR array was performed to further characterize the SCL.

The array demonstrated that there were increases in the expression of 15 genes and decreases in the expression of 9 genes in the SCL in comparison to the expression in A549 cells (Fig. 4A and B). The 15 increased genes were COL4A2, COL6A1, COL6A2, FN1, ITGA2, ITGA3, ITGA4, ITGA5, KAL1, LAMA1, LAMB3, MMP14, SPARC, TIMP2, and TNC (Table I).
The 9 genes with an decreased expression were CNTN1, COL12A1, COL1A1, VCAN, ITGA1, ITGA6, MMP7, SPP1, and TGFBI (Table II).

\section{Discussion}

In this study, we reported the characterization of cells derived from endarterectomized thrombotic tissues obtained from patients with CTEPH. These cells were defined by their morphology and immunohistochemical staining as SCL (Fig. 1A-C). The SCL were isolated from passaged myofibro- 
blast-like cells which had lost their aSMA expression (Fig. 1B) and had morphologically changed from spindle-shaped cells to pleomorphic cells characterized by large nuclei (Fig. 1A). In vitro, these SCL displayed anchorage-independent growth and hyperproliferative, invasive and tumorigenic behavior (Fig. 1D-H), raising the question whether pulmonary vessel wall cell transdifferentiation, dedifferentiation, and/or transformation play a role in the development of pulmonary intimal sarcoma.

Angiogenesis, evasion of apoptosis, self-sufficiency in growth signals, insensitivity to anti-growth signals and tissue invasion are considered the features that characterize a malignant cell, and were described in the landmark paper entitled 'Hallmarks of Cancer' by Hanahan and Weinberg (13). We herein demonstrated that SCL from endarterectomized tissue were hyperproliferative (Fig. 1D), anchorage-independent (Fig. 1E and F), invasive (Fig. 1G) and could grow serumindependently (Fig. 1H). All of these traits displayed in vitro assays reflect cancer-defining mechanisms, thus suggesting that, as the SCL, intimal sarcoma cells might originate from pluripotent mesenchymal-like cells residing in the conduit vessel endothelium.

The tumorigenic potential of the SCL that were isolated from the myofibroblast-like cells was further demonstrated in SCID mice (Fig. 2A-C). However, these cells were isolated from a single patient. Therefore, it remained unclear whether the ex vivo conditions, i.e., factors contained in the culture medium, allowed or induced this transformation or transdifferentiation. Whether there is indeed only one cell type which has the high tumorigenic potential also remains unclear, however, there may be at least two possible sources of the tumorgenic SCL: i) a resident stem-like fibroblast which grows after intimal injury, and ii) a bone marrow-derived precursor cell which migrates to injured arteries during or after thrombus formation.

We reviewed the mechanistic basis of the vascular lesions in PAH, comparing them with each of the cancer-defining mechanisms (13-15). Given this quasi-neoplastic lung vascular cell growth and the cancer-defining mechanisms demonstrated in the cells in this study, it raises the question whether the cells contained in the endarterectomized tissue of the patients with CTEPH possess a latent malignant potential. However, the SCL were isolated from specimens obtained from only one PEA subject, and the SCID mice injected with sarcoma-like cells developed tumors only from the cells isolated from this patient. The conduit vessel endothelium in CTEPH does not exhibit quasi-neoplastic potential, and CTEPH is completely different from neoplastic disease.

Mesenchymal stem cells (MSCs) have the capacity for limitless replicative potential as malignant cells, and could transform themselves from a normal phenotype into a malignant phenotype after in vitro passages (16). After intravenous injection of MSCs into the tail veins of mice, these cells could expand rapidly within the lung parenchyma, forming osteosarcoma-like lesions (17). In this study, the bone marrow-derived MSCs which migrate to injured arteries during or after thrombus formation may have developed into the SCL under in vitro conditions. However, the SCL could grow along the intimal surface of the pulmonary artery in a sheet-like form and result in the occlusion of the artery (Fig. 3A, B and D), suggesting that the SCL were different from MSCs in terms of their behavior and tumor progression. This indicates that the SCL may themselves have vascular cell-like potential which leads to their affiliation with the intimal surface of the pulmonary artery, and may be shared with pulmonary intimal sarcoma. This is the reason why our investigation into the characteristics of the SCL may elucidate the mechanism of pathogenesis of pulmonary arterial intimal sarcoma.

Although the SCL grew along the intimal surface of the pulmonary artery, the A549 cells expanded rapidly within the lung parenchyma, forming lung cancer-like lesions (Fig. 3C), and resulted in the formation of metastatic lesions in other organs (Fig. 3D). The differences between the mesenchymal cells and epithelial cells may be not sufficient to explain the observed differences between the SCL and A549 cells in tumorigenicity, because MSCs injected intravenously have the potential to develop into tumor-like lesions within the lung parenchyma, similar to A549 cells. Alterations in the expression of extracellular matrix and adhesion molecule genes (Fig. 4A and B) may explain the differences in tumorigenicity between the SCL and A549 cells.

Cell adhesion molecules, including integrins, are receptors located on the cell surface, through which cells can receive important signals from their surroundings, i.e., the basement membrane and extracellular matrix. Laminin is one of the basement membrane proteins, signals from which are transduced through integrin $\alpha 3 \beta 1$ to activate the Akt signaling pathway. This activated pathway induces anti-apoptotic effects on these cells (18). The increase in the expression of laminin and integrin $\alpha 1$ genes in the SCL in comparison to A549 cells (Fig. 4A) (Table I) suggests that there was activation of the Akt pathway in the SCL, which may be related to the different cell behaviors between the SCL and A549 cells.

Matrix metalloproteinase (MMP)-7 exhibits proteolytic activity against components of the extracellular matrix (ECM). MMP-7 is frequently overexpressed in invasive cancers of various organs, such as the colon (19), liver (20), lungs (21), and breast (22). Indeed, MMP-7 induces cancer cell invasion under in vitro conditions $(19,20,23)$. The observed decrease in the expression of MMP-7 mRNA (Fig. 4B) (Table II) supports our finding that there were no microscopically visible lesions in any other organs after intravenous injection of SCL, although there were metastatic lesions after intravenous injection of A549 cells (Fig. 3D).

This is, to the best of our knowledge, the first description and investigation of cells with in vitro and in vivo tumorigenic potential that were isolated from the surgically removed thrombotic material of a patient with CTEPH. Whether, and by what mechanism, these cells with a tumorigenic potential contribute to the development of pulmonary intimal sarcoma remains speculative. However, a further investigation of the affinity of SCL for vascular surfaces in this mouse model may elucidate the mechanism underlying the development of pulmonary arterial intimal sarcoma.

\section{Acknowledgements}

This study was supported by Research Grants for the Respiratory Failure Research Group and the Cardiovascular Diseases (19-9, 22-33) from the Ministry of Health, Labor and Welfare, Japan, a Grant-in-Aid for Scientific Research (Category C 22590851) from the Japanese Ministry of Education and Science, The Cardiovascular Research Fund, and the Takeda 
Science Foundation. K.T. has received honoraria for lectures from Glaxo Smith Kline, Actelion Pharmaceutical Ltd. N.T. has received honoraria for lectures from Actelion, Glaxo Smith Kline, Astellas and Pfizer and research grant support from Actelion Pharmaceutical Ltd. We thank Toshifumi Umemiya in the Department of Molecular and Tumor Pathology, Graduate School of Medicine, Chiba University, for the histological analysis of the mouse tumors.

\section{References}

1. Fedullo PF, Kerr KM, AugerWR, Jamieson SW and Kapelanski DP: Chronic thromboembolic pulmonary hypertension. Semin Respir Crit Care Med 21: 563-574, 2000.

2. Moser KM, Daily PO, Peterson K, Dembitsky W, Vapnek JM, Shure D, Utley J and Archibald C: Thromboendarterectomy for chronic, major vessel thromboembolic pulmonary hypertension: immediate and long-term results in 42 patients. Ann Intern Med 107: 560-565, 1987.

3. Jamieson SW, Kapelanski DP, Sakakibara N, Manecke GR, Thistlethwaite PA, Kerr KM, Channick RN, Fedullo PF and Auger WR: Pulmonary endarterectomy: experience and lessons learned in 1,500 cases. Ann Thorac Surg 76: 1457-1464, 2003.

4. Maruoka M, Sakao S, Kantake M, Tanabe N, Kasahara Y, Kurosu K, Takiguchi Y, Masuda M, Yoshino I, Voelkel NF and Tatsumi K: Characterization of myofibroblasts in chronic thromboembolic pulmonary hypertension. Int J Cardiol: Mar 14, 2011 (Epub ahead of print)

5. Yao W, Firth AL, Sacks RS, Ogawa A, Auger WR, Fedullo PF, Madani MM, Lin GY, Sakakibara N, Thistlethwaite PA, Jamieson SW, Rubin LJ and Yuan JX: Identification of putative endothelial progenitor cells $\left(\mathrm{CD} 34^{+} \mathrm{CD} 133^{+} \mathrm{Flk}-1^{+}\right)$in endarterectomized tissue of patients with chronic thromboembolic pulmonary hypertension. Am J Physiol Lung Cell Mol Physiol 296: L870-L878, 2009.

6. Firth AL, Yao W, Ogawa A, Madani MM, Lin GY and Yuan JX: Multipotent mesenchymal progenitor cells are present in endarterectomized tissues from patients with chronic thromboembolic pulmonary hypertension. Am J Physiol Cell Physiol 298: C1217-C1225, 2010.

7. Sakao S, Hao H, Tanabe N, Kasahara Y, Kurosu K and Tatsumi K: Endothelial-like cells in chronic thromboembolic pulmonary hypertension: crosstalk with myofibroblast-like cells. Respir Res 12: 109, 2011.

8. Bloomberg RD, Butany JW, Cusimano RJ and Leask RL: Primary cardiac sarcoma involving the pulmonary artery and valve. Can J Cardiol 19: 843-847, 2003.

9. Bode-Lesniewska B, Zhao J, Speel EJ, Biraima AM, Turina M, Komminoth P and Heitz PU: Gains of 12q13-14 and overexpression of $\mathrm{mdm} 2$ are frequent findings in intimal sarcomas of the pulmonary artery. Virchows Arch 438: 57-65, 2001.
10. Gaumann A, Petrow P, Mentzel T, Mayer E, Dahm M, Otto M, Kirkpatrick CJ and Kriegsmann J: Osteopontin expression in primary sarcomas of the pulmonary artery. Virchows Arch 439: 668-674, 2001.

11. Burke AP and Virmani R: Sarcomas of the great vessels. Cancer 71: 1761-1773, 1993

12. McGlennen RC, Manivel JC, Stanley SJ, Slater DL, Wick MR and Dehner LP: Pulmonary artery trunk sarcoma: a clinicopathologic, ultrastructural, and immunohistochemical study of four cases. Mod Pathol 2: 486-494, 1989.

13. Hanahan D and Weinberg R: The hallmarks of cancer. Cell 100: 57-70, 2000.

14. Rai PR, Cool CD, King JA, Stevens T, Burns N, Winn RA, Kasper $M$ and Voelkel NF: The cancer paradigm of severe angioproliferative pulmonary hypertension. Am J Respir Crit Care Med 178: 558-564, 2008.

15. Sakao S and Tatsumi K: Vascular remodeling in pulmonary arterial hypertension: multiple cancer-like pathways and possible treatment modalities. Int J Cardiol 147: 4-12, 2011.

16. Loebinger MR, Sage EK and Janes SM: Mesenchymal stem cells as vectors for lung disease. Proc Am Thorac Soc 5: 711-716, 2008.

17. Aguilar S, Nye E, Chan J, Loebinger M, Spencer-Dene B, Fisk N, Stamp G, Bonnet D and Janes SM: Murine but not human mesenchymal stem cells generate osteosarcoma-like lesions in the lung. Stem Cells 25: 1586-1594, 2007.

18. Gu J, Fujibayashi A, Yamada KM and Sekiguchi K: Laminin$10 / 11$ and fibronectin differentially prevent apoptosis induced by serum removal via phosphatidylinositol 3-kinase/ Akt- and MEK1/ERK-dependent pathways. J Biol Chem 277: 19922-19928, 2002.

19. Adachi Y, Yamamoto H, Itoh F, Hinoda Y, Okada Y and Imai K: Contribution of matrilysin (MMP-7) to the metastatic pathway of human colorectal cancers. Gut 45: 252-258, 1999.

20. Yamamoto H, Iku S, Adachi Y, Imsumran A, Taniguchi $H$, Nosho K, Min Y, Horiuchi S, Yoshida M, Itoh F and Imai K: Association of trypsin expression with tumour progression and matrilysin expression in human colorectal cancer. J Pathol 199: 176-184, 2003.

21. Bolon I, Devouassoux M, Robert C, Moro D, Brambilla C and Brambilla E: Expression of urokinase-type plasminogen activator, stromelysin 1, stromelysin 3, and matrilysin genes in lung carcinomas. Am J Pathol 150: 1619-1629, 1997.

22. Heppner KJ, Matrisian LM, Jensen RA and Rodgers WH: Expression of most matrix metalloproteinase family members in breast cancer represents a tumor-induced host response. Am J Pathol 149: 273-282, 1996.

23. Yamamoto H, Adachi Y, Itoh F, Iku S, Matsuno K, Kusano M, Arimura Y, Endo T, Hinoda Y, Hosokawa M and Imai K: Association of matrilysin expression with recurrence and poor prognosis in human esophageal squamous cell carcinoma. Cancer Res 59: 3313-3316, 1999. 